\title{
Effect of Superficial Gas Velocity on Bubbling Fluidized Bed Behaviour in a Biomass Gasifier
}

\author{
Cornelius Agu Britt M.E. Moldestad \\ Department of Process, Energy and Environmental Technology, University of South-Eastern Norway, 3918 Porsgrunn, \\ Norway, \{Cornelius.e.agu, britt.moldestad\}@usn.no
}

\begin{abstract}
This study investigates the behaviour of bubbling fluidized beds in biomass gasification processes based on the variation of superficial gas velocity at different temperatures and air flowrates. In the paper, the operating window is defined as the gas velocity between the minimum fluidization and slugging velocities, which are computed using the correlations in the literature. The analysis shows that the operating gas velocity depends on the amount of char accumulated in the bed. An increase in the char accumulation results in higher minimum fluidization and slugging velocities of the bed mixture. This therefore suggests that the gas velocity ratio required to achieve the desired operating fluidized bed regime is higher when the biomass accumulation is considered.
\end{abstract}

Keywords: biomass, gasification, air-fuel ratio, CPFD, bubbling fluidized bed

\section{Introduction}

Fluidized beds have numerous advantages in chemical processes, for example, biomass gasification. Such benefits include the excellent gas-solid mixing that can lead to uniform heat and mass distribution within the reactor. In a biomass fluidized bed gasifier, the operation is often aided with a bed material such as sand particles of relatively higher density and smaller size than the biomass particles. The bed material also helps to achieve high solid inventory and a stable pressure drop for the case of a bubbling bed. However, one major drawback is the limitation to gas flow rate imposed by the hydrodynamics of the bed material (Kunii and Levenspiel, 1991). For a given material, the bed is in the bubbling regime when the gas velocity is not too high above the minimum fluidization velocity at the operating condition. When the gas velocity is very high, the bed may transit into slugging, turbulent flow or fast fluidization regime (Kunii and Levenspiel, 1991). The flow of slugs in a bed may result in gas bypass and high fluctuation of the bed. Different factors can influence the gas velocity during operation, which will in turn lead to changes in the bed behaviour.
An increase in the gas yield during the solid fuel conversion enhances the gas velocity at the operating temperature. With changes in temperature and pressure in the conversion process, the fluid properties as well as the particle-particle interactions may vary, causing changes in the flow velocity. In extreme cases, this may lead to changes in the fluidization type (Nemati et al., 2016). The common observations to these changes is the effect of temperature on the transition of fluidized bed regimes as have been demonstrated in different studies. Increasing the bed temperature decreases the minimum fluidization velocity of Geldart A and B particles and increases those of Geldart D particles (Pattipati and Wen, 1981; Botterill et al., 1982). In addition, the gas velocities at the onset of slugging and turbulent fluidization may also increase with increasing temperature due to changes in the fluid properties and a decrease in the bubble size (Otake et al., 1975; Hatate et al., 1990).

In designing bubbling fluidized bed reactors, selecting the suitable gas velocities for stable operations while achieving the desired gas yields and compositions is a critical issue. This study is aimed at investigating the effect of gas velocity in a bubbling fluidized bed during the biomass gasification. The study is based on the theoretical equations developed for fluidized bed behaviour. The semi-empirical models are applied to simulate the minimum fluidization and slugging velocities with and without accumulation of biomass in the bed for a given reactor size and operating condition. In addition, the possibility of solids entrainment at the operating temperature and different gas velocities is simulated using the computational particle-fluid dynamics (CPFD) code. The outcome of this study can be used as a basis to understand the influence of unconverted biomass on fluidized bed behaviour.

\section{Theory: Correlations for minimum fluidization and slugging velocities}

A fluidized bed reactor usually contains a mixture of different types of particles. Each particle type influences the behaviour of the bed. The bubble properties (size and rise velocities) and transition velocities from one regime to another differ significantly from those of pure solid 
particles. The extent to which the bed behaviour is affected by each solid component depends on the amount of the individual solids in the bed. In biomass gasification reactors, the solid particles include the raw biomass, bed material, ash and char particles. For simplicity, the ash content of the fuel can be neglected since it is relatively low compared to other particles in the bed. Raw biomass and char particles can be lumped into one solid component using their average mass density and particle size. The resulting bed is a binary mixture consisting of the lumped biomass and bed material particles.

The minimum fluidization velocity of a binary mixture of biomass and bed material can be obtained from different correlations ( $\mathrm{Si}$ and Guo, 2008; Kumoro et al., 2014) for a given amount of biomass particles. In general, the minimum fluidization velocity of a bed can be computed by balancing the bed weight per unit area with the Ergun (1952) equation as expressed below

$$
\begin{aligned}
& \frac{1.75}{\varepsilon_{m f}^{3}}\left(\frac{\rho_{f} U_{m f} d_{s}}{\mu_{g}}\right)^{2}+\frac{150\left(1-\varepsilon_{m f}\right)}{\varepsilon_{m f}^{3}}\left(\frac{\rho_{g} U_{m f} d_{s}}{\mu_{g}}\right)=A r \\
& A r=\frac{d_{s}^{3} \rho_{g}\left(\rho_{s}-\rho_{g}\right) g}{\mu_{g}^{2}}
\end{aligned}
$$

where $U_{m f}$ and $\varepsilon_{m f}$ are the superficial gas velocity and bed void fraction at the minimum fluidization condition, respectively. $A r$ is the Archimedes number, $\rho_{g}$ is the fluid density, $\mu_{g}$ is the fluid dynamic viscosity, $\rho_{s}$ is the density and $d_{s}$ is the average diameter of the particles. For a bed of sand-like particles, (1) can be reduced as given in (3) (Wen and $\mathrm{Yu}, 1966$ ).

$$
U_{m f}=\frac{\mu_{g}}{\rho_{g} d_{s}}\left[-33.67+\sqrt{\left(33.67^{2}+0.0408 A r\right)}\right]
$$

Equation (1) can also be used to predict the $U_{m f}$ of a binary mixture of biomass and bed material as described in Agu et al. (2019a), where the particle diameter and density are replaced with the respective average values $d_{s m}$ and $\rho_{s m}$ for the mixture. The mixture void fraction $\varepsilon_{m f m}=1-\alpha_{m f m}$ is computed from (Agu et al., 2019a)

$$
\begin{aligned}
& \alpha_{m f m}=\frac{1-\varepsilon_{m f p}}{\left(\left(1-\varepsilon_{m f p}\right)-\varepsilon_{m f b}\left(1-\left(\frac{d_{s p}}{d_{s b}}\right)^{\beta x_{p}}\right)\left(\frac{d_{s p}}{d_{s b}}\right)\right) \frac{y_{b}}{\left(1-\varepsilon_{m f b}\right)}+y_{p}} \\
& \beta=0.623\left(\frac{d_{s p} \rho_{s p}}{d_{s b} \rho_{s b}}\right)^{-0.61}
\end{aligned}
$$

Here, $\varepsilon_{m f p}$ and $\varepsilon_{m f b}$ are the individual void fractions of the bed material and biomass particles at minimum fluidization condition, respectively. $d_{s p}$ and $d_{s b}$, and $\rho_{s p}$ and $\rho_{s b}$ are the corresponding particle diameter and density. $y_{p}$ and $y_{b}$ are the volume fraction of the different components in the mixture, where $x_{p}$ is the mass fraction of the bed material.

The minimum slugging velocity $U_{m s m}$ of the binary mixture increases significantly with an increase in the amount of biomass in the bed (Agu et al., 2019b). For biomass volume fraction less than $40 \%$, the ratio, $U_{m s m} / U_{m s p}$ is independent of biomass properties, where $U_{m s p}$ is the minimum slugging velocity of the bed material. Correlating the results obtained in different beds of sand-wood chip and sand-wood pellet mixtures, $U_{m s m} / U_{m s p}$ can be predicted from (Agu et al., 2019b)

$$
\frac{U_{m s m}}{U_{m s p}}=e^{1.13 y_{b}}
$$

Among other models (Baeyens and Geldart, 1974; Shaul et al., 2012), the value of $U_{m s p}$ can be predicted from the following equation as given in Agu et al. (2018).

$\frac{U_{m s p}}{U_{m f p}}=1+2.33 U_{m f p}^{-0.027}\left(\varphi^{0.35} c_{t}^{a_{t}}-1\right)\left(\frac{h_{0}}{D}\right)^{-0.588}$

Here, $\varphi$ is the particle sphericity, $h_{0}$ is the initial bed height and $D$ is the bed diameter. The values of the parameters $a_{t}$ and $c_{t}$ are as described in the literature (Agu et al., 2018) depending on the Archimedes number, where $A r>400$.

The amount of biomass in a bed depends on the biomass residence time at the operating condition for a given air-fuel ratio (AFr). For a steady biomass mass flowrate $\dot{m}_{b}$, the mass fraction of biomass $x_{b}$ accumulated in a bed of mass $m_{p}$ can be estimated from the following equations proposed by Agu et al. (2019c).

$$
\begin{aligned}
& \frac{x_{b}}{1-x_{b}}=(1-\lambda) \gamma_{\text {char }}\left(t_{e}-t_{d}\right) \frac{\dot{m}_{b}}{m_{p}} \\
& t_{d}=681 X_{b}^{0.028}\left(\frac{U_{0}}{U_{m f p}}\right)^{-0.3} \\
& t_{e}=4055 X_{b}^{0.278}\left(\frac{U_{0}}{U_{m f p}}\right)^{-0.185} \\
& \gamma_{\text {char }}=0.414 X_{b}^{0.245}\left(\frac{U_{0}}{U_{m f p}}\right)^{-0.463} \\
& X_{b}=\left[4055 \frac{\dot{m}_{b}}{m_{p}}\left(\frac{U_{0}}{U_{m f p}}\right)^{-0.185}\right]^{1.385}
\end{aligned}
$$

where $0.45<\lambda<0.7$ is the fraction of time over the char residence time $\left(t_{e}-t_{d}\right)$ that measures the extent of char conversion during one cycle of an ideal plug flow process. $\gamma_{\text {char }}$ is the amount of char released at the completion of biomass devolatilization (pyrolysis) and $X_{b}$ is the ratio of the mass of biomass loaded over the period $t_{e}$ to the mass of the bed material.

\section{Computational model}

To investigate the effect of gas velocity on vertical movement of particles in hot reactors, the fluidized bed behaviour was simulated using Barracuda VR software. Barracuda is the commercially developed platform for implementing computational particle-fluid dynamics (CPFD) scheme. CPFD is based on the multiphaseparticle-in-cell (MP-PIC) concept introduced by Andrew and O'Rourke (1996). In the CPFD scheme, the Euler-Lagrangian modelling approach is applied for fluid volume and particle tracking in gas-solid systems. With the MP-PIC concept, a computational particle represents a large number of particles, which have similar properties. The grouping of particles in CPFD code makes the simulation faster, thereby increasing its application to industrial systems. Detailed descriptions of the CPFD model and its numerical scheme can be found in Chen et al. (2013). 


\section{Validation of computational model}

To validate the CPFD model, experimental data were obtained from a cylindrical pilot plant of diameter $0.1 \mathrm{~m}$ and height $1.0 \mathrm{~m}$. The properties of sand particles used as the bed material is given in Table 1 .

Table 1. Bed material and biomass at ambient conditions.

\begin{tabular}{|l|l|l|l|l|l|}
\hline Materials & $\begin{array}{l}\rho_{p} \\
(\mathrm{~kg} / \mathrm{m} 3)\end{array}$ & $\begin{array}{l}d_{s} \\
(\mathrm{~mm})\end{array}$ & $\begin{array}{l}\varphi_{s} \\
(-)\end{array}$ & $\begin{array}{l}\varepsilon_{m f} \\
(-)\end{array}$ & $\begin{array}{l}U_{m f} \\
(\mathrm{~m} / \mathrm{s})\end{array}$ \\
\hline $\begin{array}{l}\text { Wood } \\
\text { chips }\end{array}$ & 423 & 6.87 & 0.75 & 0.57 & 1.270 \\
\hline Sand & 2650 & 0.61 & 0.86 & 0.45 & 0.232 \\
\hline
\end{tabular}

In the temperature range $25-550{ }^{\circ} \mathrm{C}$, the minimum fluidization velocities of the sand particles were measured using the curves of pressure drop versus superficial air velocity at different temperatures, and then correlated as given by (13) with correlation coefficient ( $\mathrm{R}^{2}$ value) of 0.9995 , where $T_{0}=25{ }^{\circ} \mathrm{C}, \rho_{g 0}$ $=1.18 \mathrm{~kg} / \mathrm{m} 3$ and $U_{m f 0}=0.232 \mathrm{~m} / \mathrm{s}$.

$U_{m f}=\frac{\rho_{g 0}}{\rho_{g}} U_{m f 0}\left\{0.19+0.787 \exp \left[-0.0045\left(T-T_{0}\right)\right]\right\}$

Figure 1 compares the minimum fluidization velocities computed using (13) with those obtained from (3) as well as the CPFD simulations at different temperatures. All the results show a decrease in the minimum fluidization velocity with increasing temperature. Both the CPFD simulation and the Wen and $\mathrm{Yu}$ correlation agree to some extent with (13) within a certain temperature range. The results from (3) are better than those from the simulations for temperatures above $200{ }^{\circ} \mathrm{C}$. The simulation result at the ambient temperature closely matches the experimental value, but the deviation at higher temperature increases as the temperature increases. The mean absolute errors in the $U_{m f}$ predictions within $25-550{ }^{\circ} \mathrm{C}$ are $8 \%$ and $10 \%$ for (3) and the CPFD simulations, respectively. It should be noted that at higher temperatures $>550{ }^{\circ} \mathrm{C}$, the trend of the measured $U_{m f}$ may deviate, increasing the inaccuracies in both model predictions. However, for the purpose of analysis, the uncertainties in using the models to extrapolate $U_{m f}$ at higher temperatures can be neglected in subsequent sections.

\section{Results and discussion}

For particle size as large as $600 \mu \mathrm{m}$, the inlet superficial gas velocity used in most studies on bubbling fluidized bed gasification is within $2-3$ times the minimum fluidization velocity of the bed material. When biomass is introduced in the reactor, the increase in the gas flowrate increases the gas velocity through the bed at the operating conditions. Assuming a full conversion, the total mass flowrate of gas at steady state can be obtained as $\left(\dot{m}_{\text {air }}+\dot{m}_{b}\right)$, neglecting the ash content of the fuel. Here, $\dot{m}_{\text {air }}$ and $\dot{m}_{b}$ are the mass flowrates of air and

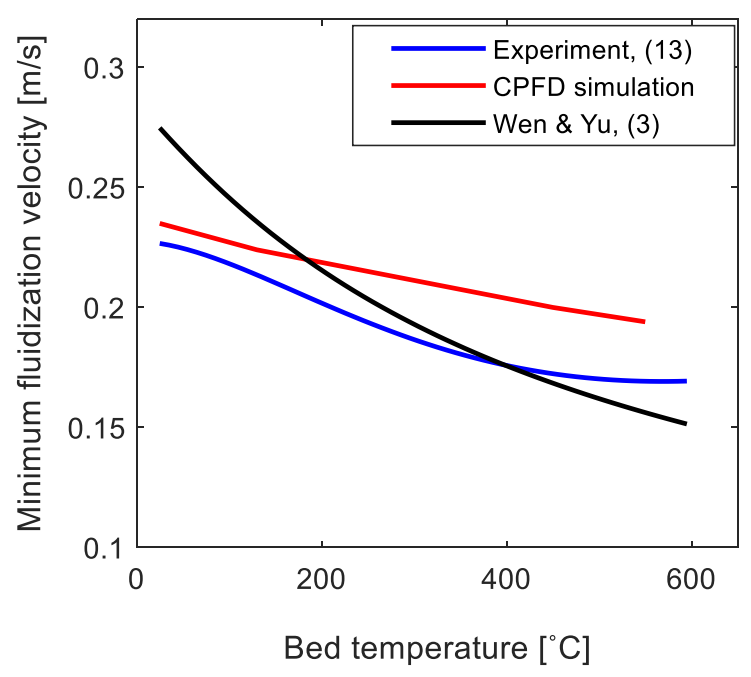

Figure 1. Variation of minimum fluidization velocity with temperature, comparing experimental data with the CPFD simulation results and the Wen \& Yu (1966) correlation; material: $610 \mu \mathrm{m}$ sand particles.

biomass, respectively. Considering gasification of wood chips (with properties reported in Table 1) at an equivalence ratio of 0.25 , a value of 1.5 can be obtained for air to biomass mass flowrate ratio. Based on this ratio, and neglecting the difference between the air density and the total gas density, the superficial gas velocity in the bed at full conversion can be approximated to $1.66 U_{0}$, where $U_{0}$ is the superficial air velocity at the operating condition. The effect of this total gas velocity depends on how evenly the bed solid species are mixed since biomass particle segregation can occur within the bed despite the fuel feeding position. Assuming a perfect mixing of the solid particles, the gas velocity can be considered uniform over the entire bed volume.

\subsection{Neglecting the biomass accumulation}

Figure 2(a) shows the influence of temperature on the bed behaviour of the $610 \mu \mathrm{m}$ sand particles at two different constant air mass flowrates, $\dot{m}_{\text {air }}=$ $2\left(\rho U_{m f}\right)_{o p t} A_{0}$ and $\dot{m}_{\text {air }}=3\left(\rho U_{m f}\right)_{\text {opt }} A_{0}$, which are assumed to represent cases without any reaction. Figure 2(b) shows the behaviour for the corresponding cases at full conversion. Here, the values of $\left(\rho U_{m f}\right)_{o p t}$ are obtained at the reactor operating temperature $900{ }^{\circ} \mathrm{C}$, in which $U_{m f}=0.187 \mathrm{~m} / \mathrm{s}$ based on the correlation given by (13). The plotted data are the superficial gas velocities $U_{0}$ and the transition velocities $U_{m f}$ and $U_{m s}$ at different temperatures. The minimum slugging velocity was computed from (7) at the bed aspect ratio, $h_{0} / D=2.5$ and the superficial air velocity was obtained from $U_{0}=\dot{m}_{\text {air }} / \rho A_{0}$, where the air density $\rho$ is at the different temperatures. Due to decreasing gas density, the operating gas velocity $U_{0}$ increases with an increase in temperature at a constant mass flowrate. The 


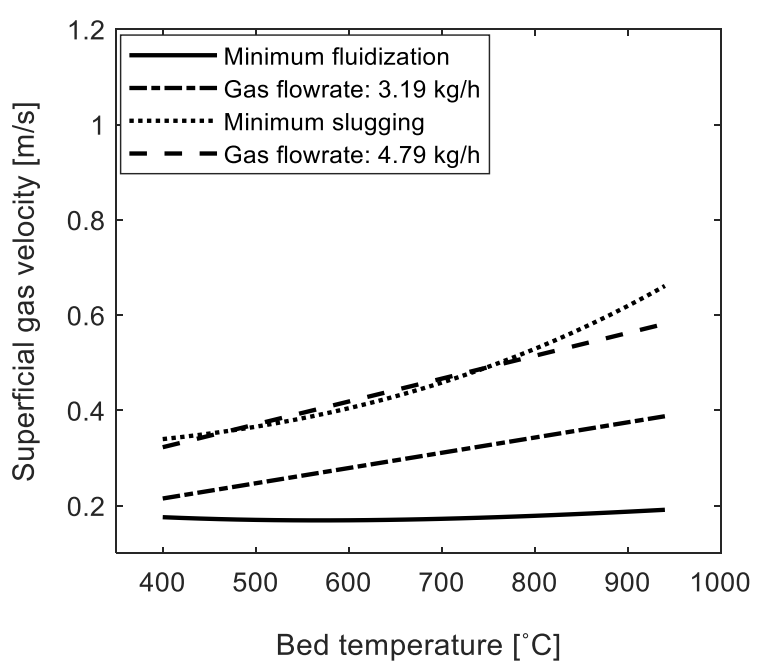

(a)

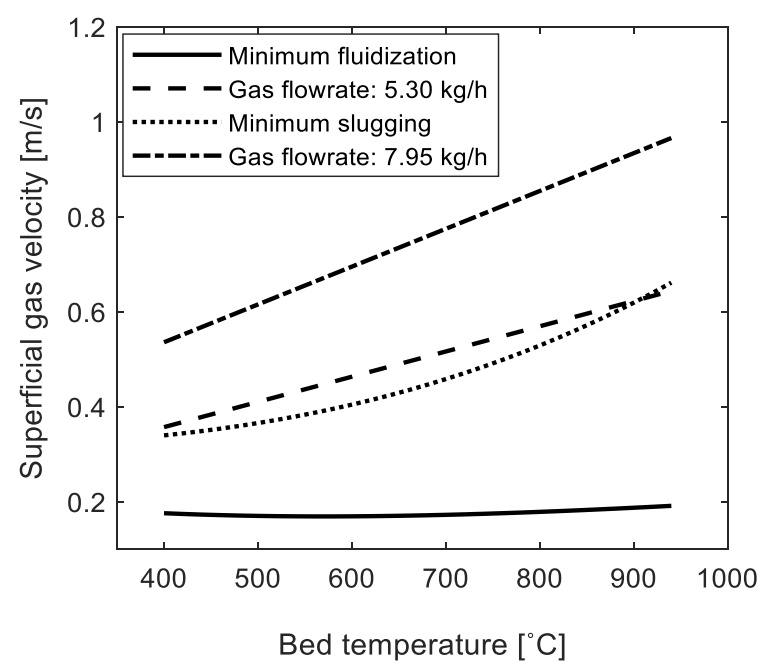

(b)

Figure 2. Behaviour of bed of sand particles, $610 \mu \mathrm{m}$ at different temperatures and constant mass flowrates, $\dot{m}_{\text {air }}$

(a) $\left(2 \rho U_{m f}\right)_{o p t} A_{0}=3.19$ and $\left(3 \rho U_{m f}\right)_{o p t} A_{0}=4.79$ $\mathrm{kg} / \mathrm{h} \mathrm{(b)} 1.66 \cdot\left(2 \rho U_{m f}\right)_{o p t} A_{0}=5.30$ and

$1.66 \cdot\left(3 \rho U_{m f}\right)_{o p t} A_{0}=7.95 \mathrm{~kg} / \mathrm{h}$, where $A_{0}=\pi D^{2} / 4$.

gas velocity $U_{m s}$ at the onset of slugging also increases as the temperature is increased. From the figures, the bed is fluidized (i.e. $U_{0}>U_{m f}$ ) within the given temperature range for the respective mass flowrates.

With an increase in temperature, the bed remains in the bubbling regime until the operating velocity line crosses the minimum slugging velocity line. This never occurs in Figure 2(a) even at the higher mass flowrate. This shows that if the bed is maintained at a gas velocity of $3 U_{m f}$, the bed will remain in the bubbling regime at the operating conditions. However, with a full conversion, the behaviour is completely different as shown in Figure 2(b); the bed slugs at both total mass flowrates.

In a bed of larger particles, bubbles can easily grow into slugs. Aside reduction in the gas residence time at higher gas velocities, there are also possibilities of particle attrition and entrainment of fines especially when the reaction column is not tall enough. If a complete reaction is assumed at the operating temperature, the increase in the total gas flowrate may also increase these effects. The effect of gas velocity on the distribution of solids along the bed axis is shown in Figure 3 for the $610 \mu \mathrm{m}$ sand particles. The gas flowrates are the same as those used in Figure 2. In the CPFD simulations, the initial bed height was $25 \mathrm{~cm}$ and the initial solids fraction was 0.55 . The contours of solids fraction (captured after $20 \mathrm{~s}$ ) show that as gas velocity increases, the possibility of particles being dragged into the freeboard increases. The time-averaged solids fractions at different positions are shown in Figure 3(e). In these results, the flow regime of the bed at different gas velocities can be identified as described in Kunii and Levenspiel (1991). The result shows that at the gas velocities $U_{0}=2 U_{m f}$ and $U_{0}=3 U_{m f}$, the bed is in the bubbling regime, but in the slugging/turbulent flow regime at the two larger gas velocities. In addition, Figure 3(e) clearly shows that the amount of solids in the freeboard increases as the gas flowrate is increased, and the particles reach higher up in the column when a higher velocity is used. There are traces of solids in the column up to a height of $70 \mathrm{~cm}$. At this position, the respective solids fractions are $4 \cdot 10^{-7}, 6 \cdot 10^{-6}, 6 \cdot 10^{-6}$ and $5 \cdot 10^{-5}$. Especially for the velocity $U_{0}=4.98 U_{m f}$, this shows that there is a possibility of particle entrainment from the column.
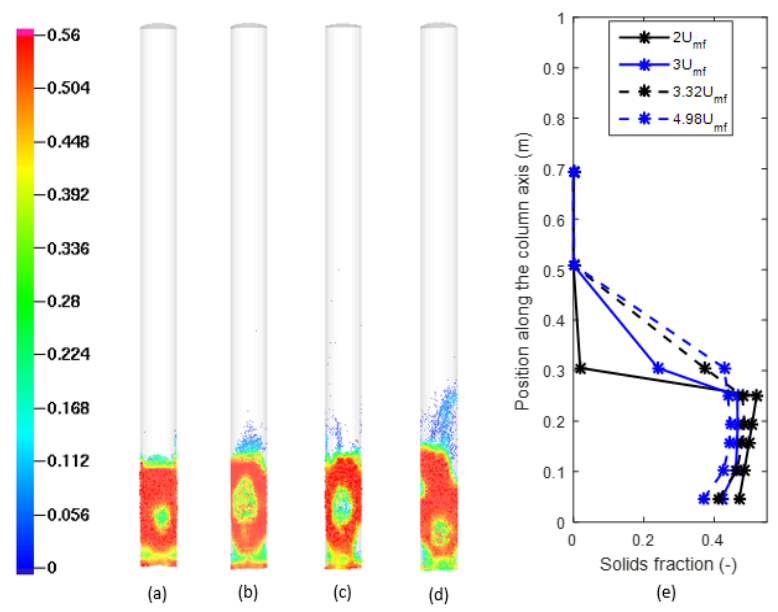

Figure 3. Bed behaviour simulated using CPFD Barracuda based on the $610 \mu \mathrm{m}$ sand particles at $900{ }^{\circ} \mathrm{C}$, showing the solids fraction distributions captured after 20 sec at different superficial air velocities (a) $U_{0}=2 U_{m f}$ (b) $U_{0}=3 U_{m f}$ (c) $U_{0}=3.32 U_{m f}$ (d) $U_{0}=4.98 U_{m f}$ and (e) the time-average axial distribution of solids fraction.

\subsection{Considering the biomass accumulation}

By considering the biomass accumulation, (8) was used to estimate the amount of unconverted char in the 


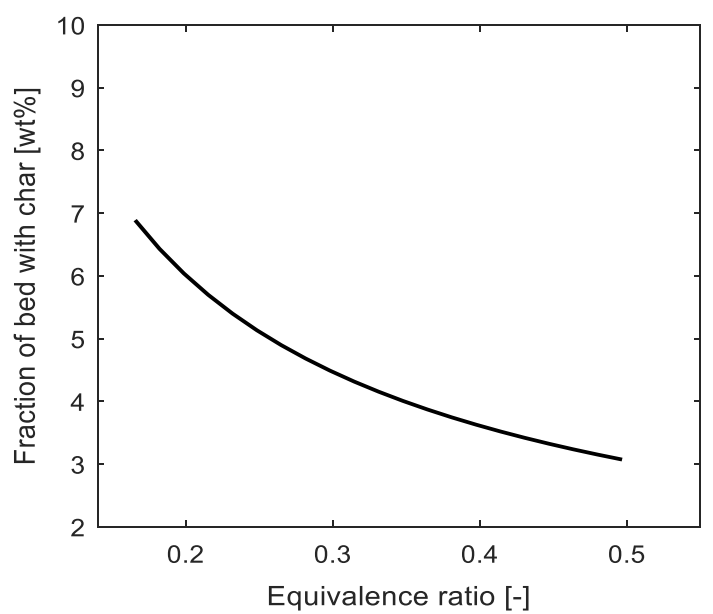

(a)

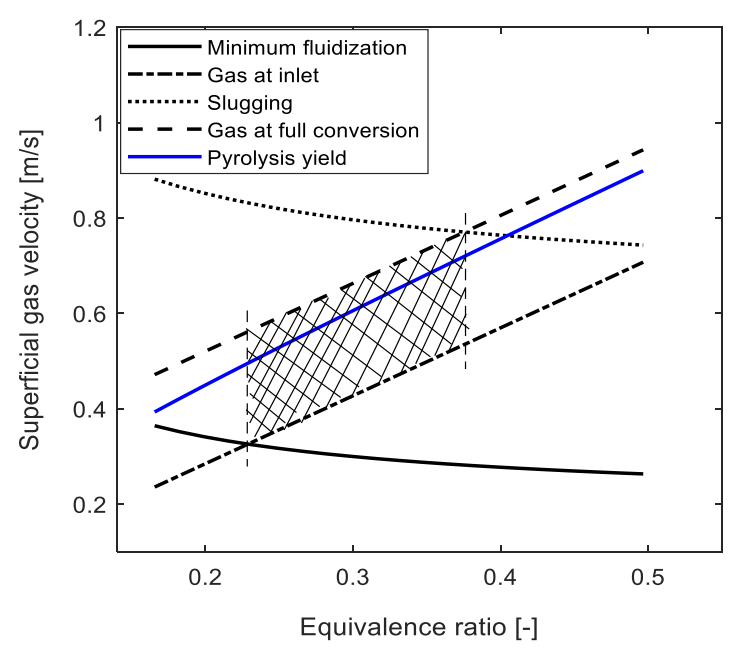

(b)

Figure 4. Behaviour of a bubbling fluidized bed gasifier at constant biomass flowrate, $900{ }^{\circ} \mathrm{C}$ and different equivalence ratios (a) amount of unconverted char particles (b) gas velocity across the bed, showing the safe operating window.

bed at the given operating conditions. Figure 4(a) shows the values of $x_{b}$ at a constant biomass flowrate $2 \mathrm{~kg} / \mathrm{h}$ and different equivalence ratios (ER) defined as the ratio of the actual air-fuel ratio to the air-fuel ratio required for stoichiometry combustion of biomass. The equivalence ratio measures the relative amount of oxygen supplied, and for biomass gasification, ER $<1$. The results shown in Figure 4 are based on a $10 \mathrm{~cm}$ diameter bed containing the $610 \mu \mathrm{m}$ sand particles at initial height of $25 \mathrm{~cm}$. As shown in the figure, $x_{b}$ decreases with increasing ER due to increasing amount of the fuel particles converted. The bed behaviour at the different ER values is shown in Figure 4(b). While the values of $U_{m f}$ and $U_{m s}$ of the bed mixture decrease, the gas velocity through the bed increases with increasing equivalence ratio. For ER $<0.23$, the incoming air velocity is too low to maintain the fluidization of the bed as the accumulation is relatively high. However, with an increase in the total gas flowrate at the completion of biomass pyrolysis, the bed is fluidized even at ER value of 0.15 . It should be noted that at a low air velocity, the conversion will be delayed, thus the full conversion gas velocity will be rarely achieved at equivalence ratio $<1$. If the total gas yield at full conversion acts on the bed evenly, the bed will remain in the bubbling regime up to $E R=0.38$. The shaded portion in Figure 4(b) should therefore represent the safe operating window for the system. At the 0.38 equivalence ratio, the incoming air velocity, $U_{0} / U_{m f p}=3$. On the contrary, when the biomass accumulation is not considered, the maximum air velocity within the bubbling window at $900{ }^{\circ} \mathrm{C}$ is $U_{0} / U_{m f p}=2$ as can be seen in Figure 2. This indicates that the amount of unconverted biomass must be considered when selecting the gas velocity for a fluidized bed operation.

\section{Conclusions}

This study investigated the behaviour of bubbling fluidized bed in a biomass gasification reactor to illustrate how the operating window can be established. The study applied different correlations proposed in the literature for predicting the minimum fluidization and slugging velocities of a given bed including those of binary mixtures of biomass and bed material. Based on the analysis, the amount of unconverted char particles plays a significant role in the hydrodynamics of the bed, and thus must be considered when selecting the gas velocity for stable operations.

\section{References}

C.E. Agu, C. Pfeifer, and B.M.E. Moldestad. Prediction of void fraction and minimum fluidization velocity of a binary mixture of particles: Bed material and fuel particles. Powder Technology, 349: 99 - 107, 2019(a).

C.E. Agu, C. Pfeifer, L.-A. Tokheim, and B.M.E. Moldestad. Behaviour of biomass particles in a bubbling fluidized bed: A comparison between wood pellets and wood chips. Chemical Engineering Journal, 363: 84 $-98,2019$ (b).

C.E. Agu, C. Pfeifer, M. Eikeland, L.-A. Tokheim, and B.M.E. Moldestad. Models for predicting average bubble diameter and volumetric bubble flux in deep fluidized beds. Industrial \& Engineering Chemistry Research, 57: 2658 - 2669, 2018.

C.E. Agu, C. Pfeifer, M. Eikeland, L.-A. Tokheim, and B.M.E Moldestad. Measurement and characterization of biomass mean residence time in an air-blown bubbling fluidized bed gasification reactor. Fuel, 253: 1414 - 1423, 2019(c).

M.J. Andrews and P.J. O'Rourke. The multiphase particleincell (MP-PIC) method for dense particulate flows. International Journal of Multiphase Flow, 22: 379 - 402, 1996.

J. Baeyens and D. Geldart. An Investigation into slugging fluidized beds. Chemical Engineering Science, 29: 255 $-265,1974$. 
J.S.M. Botterill, Y. Teoman, and K.R. Yuregir. The effect of operating temperature on the velocity of minimum fluidization, bed voidage and general behaviour. Powder Technology, 31: 101 - 110, 1982.

C. Chen, J. Werther, S. Heinrich, H.-Y. Qi, and E.-U. Hartge. CPFD simulation of circulating fluidized bed risers. Powder Technology, 235: 238 - 247, 2013.

S. Ergun. Fluid flow through packed column. Chemical Engineering Progress, 48: 89 - 94, 1952.

Y. Hatate, K. Ijichi, Y. Uemura, M. Migita, and D.F. King. Effect of bed temperature on bubble size and bubble rising velocity in a semi-cylindrical slugging fluidized bed. Journal of Chemical Engineering of Japan, 23: 765 - 767, 1990.

A.C. Kumoro, D.A. Nasution, A. Cifriadi, A. Purbasari, and A.F. Falaah. A new correlation for the prediction of minimum fluidization of sand and irregularly shape biomass mixtures in a bubbling fluidized bed. International Journal of Applied Engineering Research, 9(23): 21561 - 21573, 2014.

D. Kunii and O. Levenspiel. Fluidization Engineering, 2nd ed., Butterworth - Heinemann, Washington Street, USA, 1991.
N. Nemati, R. Zarghami, and N. Mostoufi. Investigation of hydrodynamics of high temperature fluidized beds by pressure fluctuations. Chemical Engineering \& Technology, 39: 1527 - 1536, 2016.

T. Otake, S. Tone, M. Kawashima, and T. Shibata. Behaviour of rising bubbles in a gas fluidized bed at elevated temperature. Journal of Chemical Engineering of Japan, 8: 388 - 392, 1975.

R.R. Pattipati and C.Y. Wen. Minimum fluidization velocity at high temperature. Industrial \& Engineering Chemistry Process Design and Development, 20: 705 - 708, 1981.

S. Shaul, E. Rabinovich, and H. Kalman. Generalized flow regime diagram of fluidized beds based on the height to bed diameter ratio. Powder Technology, 228: 264 - 271, 2012.

C. Si and Q. Guo. Fluidization characteristics of binary mixtures of biomass and quartz sand in an acoustic fluidized bed. Industrial \& Engineering Chemistry Research, 47: 9773 - 9782, 2008.

C.Y. Wen and Y.H. Yu. A generalized method for predicting the minimum fluidization velocity. AIChE Journal, 12: $610-612,1966$. 